\title{
BMJ Open Use of humour in medical education: a survey of students and teachers at a medical school in China
}

\author{
Yan-Ping Liu, ${ }^{1}$ Lei Sun, ${ }^{2}$ Xiao-Fen Wu, ${ }^{1}$ Yi Yang, ${ }^{1}$ Cun-Tai Zhang, ${ }^{1}$ \\ Hong-Lian Zhou, ${ }^{1}$ Xiao-Qing Quan ${ }^{1}$
}

To cite: Liu Y-P, Sun L, Wu X-F, et al. Use of humour in medical education: a survey of students and teachers at a medical school in China. BMJ Open 2017;7:e018853. doi:10.1136/ bmjopen-2017-018853

- Prepublication history and additional material for this paper are available online. To view these files, please visit the journal online (http://dx.doi. org/10.1136/bmjopen-2017018853).

Y-PL and LS contributed equally.

Received 25 July 2017

Revised 30 0ctober 2017

Accepted 1 November 2017
CrossMark

${ }^{1}$ Department of Geriatrics, Tongji Hospital, Tongji Medical College, Huazhong University of Science and Technology, Wuhan, China ${ }^{2}$ Department of Oncology, Tongji Hospital, Huazhong University of Science and Technology, Wuhan, China

Correspondence to

Dr Xiao-Qing Quan;

quanxiaoqing@hotmail.com

\section{ABSTRACT}

Objective Humour is a powerful resource in medical education. The purpose of this study is to investigate what students and teachers think about the use of humour. What challenges do teachers face in using humour and how they address them are also the subject of the present study. Design Separate cross-sectional questionnaire surveys. Setting Tongji Medical College and Tongji Hospital in China.

Participants 327 students at Tongji Medical College and 165 physician teachers at Tongji Hospital in China.

Main outcome measures The primary study outcome was assessed by proportion.

Results $87 \%$ of student and teacher respondents agreed with using humour in the didactic setting. They felt humour fostered a positive didactic atmosphere. Interesting clinical case was the most frequently used humour type by teachers and considered the most effective by students. Lack of humorous materials related to the lecture subject was the main challenge to humour use cited by teachers. Collecting humorous materials in teacher's daily work and life, observing teachers with a reputation for successfully using humour, and efficiently using the internet-enhanced humour use ability.

Conclusion The present study confirms that most medical students and physician teachers support the use of humour in medical didactics, with particular strategies aiding its use and positive impact.

\section{INTRODUCTION}

Acquiring basic clinical skills is the primary mission of medical students. ${ }^{1}$ Historically, education has been considered as a solemn endeavour, and using humour in the learning process has not been valued or encouraged. In recent years, there has been a shift in societal attitudes towards the adoption of a more relaxed learning environment and an increased emphasis on making learning more enjoyable. $^{2-6}$

Humour can affect psychological, physiological and immunological functions by humanising, encouraging, defusing, illustrating and reducing anxiety. ${ }^{7-9}$ McCoy et al interviewed 108 first-year medical students, the result of the study indicated

\section{Strengths and limitations of this study}

- This is the first questionnaire survey of medical students and physician teachers regarding use of humour in medical education.

- The study provides useful information of medical student and teacher's opinions on using humour in the theoretical lecture and identifies appropriate and inappropriate humour behaviours.

- The main limitation of this study is that it is a singlecentre study on a relatively small study population.

that humour could foster engagement through demonstrating interest in the activities. ${ }^{10}$ It has been found that students might be more motivated to learn and get involved in a positive classroom atmosphere..$^{21-13}$ Several studies have examined how humour can help students to reduce stress, promote creativity, increase motivation and assimilate knowledge more quickly. ${ }^{3}{ }^{12}$ 14-16 Informal observation suggests that the use of humour is widespread in medical education. At the Sydney Children's Hospital, almost $80 \%$ of physicians used humour in their teaching sessions, and regularly elicited laughter from their students. ${ }^{17}$

A positive relationship was found between humour and student's test performance. ${ }^{151819}$ While some forms of inappropriate humour with discriminatory or aggressively may degrade or hurt students. Humour related to one's misfortune or mistake might put listeners down and discourage their enthusiasm. ${ }^{20-24}$ Teachers need to avoid the use of inappropriate humour in medical teaching.

Although widely practised, the use of humour in medical teaching has not been adequately studied. In addition, there is scant literature on the difficulties and challenges for humour teaching in the medical school setting. Research on humour use might help medical teachers to prepare useful forms of 
humour for teaching, and might provide other benefits on teaching style, method and content.

The purpose of this study was to assess opinions of medical students and teachers about using humour and to explore what would influence the teachers' use of humour in medical education.

\section{METHODS}

\section{Study design}

Quantitative data were generated from a self-administered survey questionnaire.

\section{Participants' population}

The present study was conducted at Tongji Medical College and Tongji Hospital (Huazhong University of Science and Technology, Wuhan City, Hubei Province, China) from November 2014 to June 2015. Under the approval of the college research and ethics committee, a cross-sectional study was conducted among medical undergraduates at Tongji Medical College and physician teachers at Tongji Hospital. All study participants signed informed consent forms before enrolment.

\section{Survey questionnaire}

After reviewing a wide variety of literature related to the use of humour and medical education, published in international or Chinese academic journals in the last 50 years, we established two primary questionnaires for medical students and physician teachers separately. We conducted a pilot study to ascertain any perceived problems and assess the acceptability of the questions. The paper-based primary questionnaires were reviewed by a random sample of 50 medical students at Tongji Medical College and 30 physician teachers at Tongji Hospital. Each item in the questionnaire was critically evaluated. Recommendations from the students and teachers were used to develop the final questionnaires. A total of 327 medical students and 165 physician teachers responded to the paper-based final questionnaire. Participant characteristics were summarised in online supplementary tables 1 and 2.

The student questionnaire comprised of eight questions related to attitudes towards the use of humour in the theoretical lecture. For all the questions in our study, there was no option for respondents to suggest other responses. Writing survey questions are listed below in the order in which they were presented to respondents.

- What is the proportion of the medical curriculum during which you felt bored? (Single-choice)
A. Always $(100 \%)$
B. Usually $(80 \%)$
C. Often $(60 \%)$
D. Sometimes $(40 \%)$
E. Seldom (20\%)
F. Rarely (10\%)
G. Never $(0 \%)$
- Do you agree with using humour in medical teaching? (Single-choice)

A. Strongly agree

B. Agree

C. Neutral

D. Disagree

E. Strongly disagree

- What are the benefits of using humour in medical teaching? (Multiple-choice)

A. Create a relaxed classroom atmosphere

B. Make learning experience more positive and enjoyable

C. Help student-instructor interaction by improving rapport

D. Focus student's attention on the theme

E. Remember more information over time

- How many times of humour do you think is appropriate in a 45-min theoretical course (each class period is usually $45 \mathrm{~min}$ in Tongji Medical College)? (Single-choice)
A. 1
B. 2
C. 3
D. 4
E. 5
F. $>5$

- Which forms of humour did teachers use in past medical courses? (Multiple-choice)

A. Interesting clinical cases

B. Spontaneous, ad libbed humour

C. Cartoons or videos

D. Skits

E. Questions or multiple-choice items

F. Planned, non-spontaneous humour

G. Network catchwords

H. Opening jokes

I. Quotations or analogies

- Which do you consider is the most effective form of humour, and please rank them using a 9-point Likert scale ranging from most effective (9 points) to least effective (1 point).

A. Interesting clinical cases

B. Spontaneous, ad libbed humour

C. Cartoons or videos

D. Planned, non-spontaneous humour

E. Opening jokes

F. Questions or multiple-choice items

G. Network catchwords

H. Skits

I. Quotations or analogies

- What do you think constitutes inappropriate humour during teaching? (Multiple-choice)

A. Sarcasm

B. Mockery

C. Humour irrelevant to the course material

D. Instructor appearing as performer

E. Ridicule

- Which disadvantages do you think inappropriate humour may have during teaching? (Multiple-choice)

A. Spend time on an irrelevant subject

B. Distract attention 
C. Disrupt solemn atmosphere

D. Cannot help improve classroom performance

Similarly, a survey was conducted among physician teachers. The physician questionnaire comprised of eight questions to investigate the aforementioned questions, and difficulties in using humour and how to address them.

- What is the motivation to use humour? (Multiple-choice)

A. To foster a relaxed classroom atmosphere

B. To obtain self-satisfaction as an instructor

C. To foster joviality brought on by student's laughter

D. To get positive feedback during instructor evaluation

- Which difficulty do you face when using humour in teaching? (Multiple-choice)

A. Lack of appropriate humour related to course material

B. Humour doesn't reach the expected effect

C. Depression or frustration when humour falls flat

D. Time-consuming

- Which of the following options can help to use humour during teaching? (Multiple-choice)

A. Collecting humorous materials during daily work and life

B. Making full use of network resources

C. Classroom observation of teachers with a reputation of successfully using humour

D. Preparing the teaching content in advance

E. Reading books and articles about humour

F. Professional training provided by medical college

In the same questionnaire, data were also collected on physician teachers' medical discipline, gender, academic rank, age and teaching experience in years.

\section{Statistical analysis}

Questionnaires with missing items were considered ineffective and excluded from subsequent analysis. The data collected were tabulated in Microsoft Excel 2014, and frequencies and percentages were calculated for quantitative variables. Data were demonstrated as mean \pm SEM or simple number as appropriate. The data were analysed using descriptive statistics in this study. Data collection and analysis were performed simultaneously.

\section{RESULTS}

\section{Demographic data of participants}

Three hundred and twenty-seven medical students $(96 \%$ response rate) at the Tongji Medical College responded to the questionnaire. As shown in online supplementary table $1,52 \%$ of respondents were women, with $53 \%$ aged $17-20$ years and $47 \%$ aged $21-25$ years. The proportion of students in each year (first to fifth) was 11\%, 19\%, 29\%, $26 \%$ and $15 \%$, respectively.

A total of 165 physician teachers at Tongji Hospital responded to the questionnaire (91\% response rate): $56 \%$ of respondents were men, with age ranging from 26 to 81 years, and academic rank distributed as follows: $22 \%$ professors, $50 \%$ associate professors and $28 \%$ assistant
Table 1 The attitude towards medical curriculum

\begin{tabular}{lc}
\hline & $\begin{array}{l}\text { Students } \\
(\mathbf{n = 3 2 7})\end{array}$ \\
\cline { 2 - 2 } Variables & $(\%$ Yes) \\
\hline $\begin{array}{l}\text { How often have you felt bored during the } \\
\text { medical curriculum? (Single-choice) }\end{array}$ \\
$\begin{array}{l}\text { A. Always (100\%) } \\
\text { B. Usually (80\%) }\end{array}$ \\
\hline C. Often (60\%) & 2 \\
\hline D. Sometimes (40\%) & 36 \\
\hline E. Seldom (20\%) & 34 \\
\hline F. Rarely (10\%) & 10 \\
\hline G. Never (0\%) & 3 \\
\hline
\end{tabular}

professors. Teaching experience ranged from 1 to 35 years; $27 \%$ with $1-9$ years, $35 \%$ with $10-19$ years and $38 \%$ with 20 years or more (online supplementary table 2).

\section{Opinions of medical students and teachers on humour teaching}

In the present study, $2 \%$ of students felt $100 \%$ of their classes were boring, $15 \%$ of students felt $80 \%$ of their classes were boring, $36 \%$ of students felt $60 \%$ of their classes were boring, $34 \%$ of students felt $40 \%$ of their classes were boring, $10 \%$ of students felt $20 \%$ of their classes were boring, $3 \%$ of students felt $10 \%$ of their classes were boring (table 1).

Among students, 45\% strongly agreed and 42\% agreed with using humour in medical teaching, while the corresponding percentages for teachers were $52 \%$ and $35 \%$, respectively (table 2 ). The majority of students agreed that humour could be used to create a relaxed classroom atmosphere (94\%); make the learning experience more positive and enjoyable (90\%); help studentteacher interaction by improving rapport $(82 \%)$; focus student's attention on the theme $(67 \%)$ and remember more information over time $(64 \%)$. As for teachers, the approval rates for the items above were $82 \%, 80 \%, 77 \%$, $74 \%$ and $55 \%$, respectively.

Most students emphasised that humour worked best in a small amount: two (19\%), three $(36 \%)$ or four $(21 \%)$ humorous remarks per 45-min session. Most teachers used two $(38 \%)$ or three $(31 \%)$ humorous remarks per 45-min session, while $12 \%$ used four humorous remarks. In term of the humour types used by teachers in past courses, physicians mentioned: interesting clinical cases $(70 \%)$; spontaneous, ad libbed humour $(67 \%)$; cartoons or videos $(21 \%)$; skits $(17 \%)$; questions or multiple-choice items (13\%); planned, non-spontaneous humour (12\%); network catchwords (11\%); opening jokes (7\%) and quotations or analogies (2\%) (table 2).

One area of significance in this study is how students evaluated the effectiveness of each humour type (table 3). In this study, interesting clinical case was ranked highest (mean $8 \pm 0.05$ ), followed by spontaneous, ad libbed 
Table 2 The attitude towards humour compared between physicians and students

\begin{tabular}{|c|c|c|}
\hline & $\begin{array}{l}\text { Physicians } \\
(\mathrm{n}=165)\end{array}$ & $\begin{array}{l}\text { Students } \\
(\mathrm{n}=327)\end{array}$ \\
\hline Variables & $\%$ Yes & $\%$ Yes \\
\hline \multicolumn{3}{|c|}{$\begin{array}{l}\text { Do you agree with using humour in medical teaching? } \\
\text { (Single-choice) }\end{array}$} \\
\hline A. Strongly agree & 52 & 45 \\
\hline B. Agree & 35 & 42 \\
\hline C. Neutral & 13 & 11 \\
\hline D. Disagree & 0 & 2 \\
\hline E. Strongly disagree & 0 & 0 \\
\hline \multicolumn{3}{|c|}{$\begin{array}{l}\text { What are the benefits of using humour in medical teaching? } \\
\text { (Multiple-choice) }\end{array}$} \\
\hline $\begin{array}{l}\text { A. Create a relaxed classroom } \\
\text { atmosphere }\end{array}$ & 82 & 94 \\
\hline $\begin{array}{l}\text { B. Make learning experience more } \\
\text { positive and enjoyable }\end{array}$ & 80 & 90 \\
\hline $\begin{array}{l}\text { C. Help student-instructor } \\
\text { interaction by improving rapport }\end{array}$ & 77 & 82 \\
\hline $\begin{array}{l}\text { D. Focus student's attention on } \\
\text { the theme }\end{array}$ & 74 & 67 \\
\hline $\begin{array}{l}\text { E. Remember more information } \\
\text { over time }\end{array}$ & 55 & 64 \\
\hline \multicolumn{3}{|c|}{$\begin{array}{l}\text { How many times of humour do you think are appropriate } \\
\text { during a 45-min course? (Single-choice) }\end{array}$} \\
\hline A. 1 & 5 & 4 \\
\hline B. 2 & 38 & 19 \\
\hline C. 3 & 31 & 36 \\
\hline D. 4 & 12 & 21 \\
\hline E. 5 & 9 & 14 \\
\hline F. $>5$ & 5 & 6 \\
\hline
\end{tabular}

Which form of humour have physicians used in teaching? (Multiple-choice)

\begin{tabular}{|c|c|c|}
\hline A. Interesting clinical cases & 70 & 89 \\
\hline $\begin{array}{l}\text { B. Spontaneous, ad libbed } \\
\text { humour }\end{array}$ & 67 & 67 \\
\hline C. Cartoons or videos & 21 & 27 \\
\hline D. Skits & 17 & 39 \\
\hline $\begin{array}{l}\text { E. Questions or multiple-choice } \\
\text { items }\end{array}$ & 13 & 18 \\
\hline $\begin{array}{l}\text { F. Planned, non-spontaneous } \\
\text { humour }\end{array}$ & 12 & 20 \\
\hline G. Network catchwords & 11 & 13 \\
\hline H. Opening jokes & 7 & 29 \\
\hline I. Quotations or analogies & 2 & 17 \\
\hline
\end{tabular}

humour (mean $7 \pm 0.08$ ), cartoons or videos (mean $7 \pm 0.08$ ) and planned, non-spontaneous humour (mean $6 \pm 0.08)$.

As for the potential disadvantage of using inappropriate humour in medical teaching, humour related to
Table 3 Score of humour types students considered

Students

Variables

( $n=327)$

Which do you consider to be the most effective form of humour? Please rank from most to least effective. (mean \pm SEM)
A. Interesting clinical cases
$8 \pm 0.05$
B. Spontaneous, ad libbed humour
$7 \pm 0.08$
C. Cartoons or videos
$7 \pm 0.08$
D. Planned, non-spontaneous humour
$6 \pm 0.08$
E. Opening jokes
$5 \pm 0.09$
F. Questions or multiple-choice items
$5 \pm 0.09$
G. Network catchwords
$3 \pm 0.08$
H. Skits
$2 \pm 0.07$
I. Quotations or analogies
$2 \pm 0.06$

sarcasm and mockery received low evaluations from the students $(61 \%$ and $60 \%$ disapproval rates, respectively). Students emphasised that inappropriate humour might spend time on an irrelevant subject (56\%); distract their attention $(35 \%)$; disrupt the solemn atmosphere $(13 \%)$ and cannot help improve classroom performance $(12 \%)$ (table 4).

\section{Influencing factor of humour teaching application}

As is shown in table 5, the main motivation for teachers to use humour was to foster a relaxed classroom atmosphere $(63 \%)$. Self-satisfaction $(38 \%)$ and a sense of joviality brought on by student's laughter $(35 \%)$ also were considered as helpful to inspire teachers to use humour during class. Teachers reported a variety of difficulties when using humour in teaching, including: lack of humour related to course material $(42 \%)$; humour doesn't reach

Table 4 The inappropriate types of humour

\section{Variables}

Students ( $n=327)$ $\%$ Yes

What do you think constitutes inappropriate humour during teaching? (Multiple-choice)
A. Sarcasm
61
B. Mockery 60
C. Humour irrelevant to the course material
34
D. Instructor appearing as performer 30
E. Ridicule 15

Which disadvantages do you think inappropriate humour may have during teaching? (Multiple-choice)
A. Spend time on an irrelevant subject 56
B. Distract attention 35
C. Disrupt solemn atmosphere 13
D. Cannot help improve classroom 12 performance 
Table 5 Influencing factor of humour teaching application

\begin{tabular}{ll}
\hline & Physicians (n=165) \\
\cline { 2 - 2 } Variables & (\% Yes) \\
\hline How often do you use humour in medical teaching? (Single-choice) & 2 \\
\hline A. Always (100\%) & 8 \\
\hline B. Usually (80\%) & 13 \\
\hline C. Often (60\%) & 51 \\
\hline D. Sometimes (40\%) & 16 \\
\hline E. Seldom (20\%) & 9 \\
\hline F. Rarely (10\%) & 1 \\
\hline G. Never (0\%) & \\
\hline What is the motivation to use humour? (Multiple-choice) & 63 \\
\hline A. To foster a relaxed classroom atmosphere & 38 \\
\hline B. To obtain self-satisfaction as an instructor & 35 \\
\hline C. To foster joviality brought on by student's laughter & 6 \\
\hline D. To get positive feedback during instructor evaluation & \\
\hline Which difficulty do you face when using humour in teaching? (Multiple-choice) & 42 \\
\hline A. Lack of appropriate humour related to course material & 32 \\
\hline B. Humour doesn't reach the expected effect & 26 \\
\hline C. Depression or frustration when humour falls flat & 14 \\
\hline D. Time-consuming & \\
\hline Which of the following options can help to use humour during teaching? (Multiple-choice) \\
\hline A. Collecting humorous materials during daily work and life & 70 \\
\hline B. Making full use of network resources & 29 \\
\hline C. Classroom observation of teachers with a reputation of successfully using humour \\
\hline D. Preparing the teaching content in advance & 24 \\
\hline E. Reading books and articles about humour & 21 \\
\hline F. Professional training provided by medical college & 11 \\
\hline
\end{tabular}

the expected effect (32\%); depression or frustration when humour falls flat $(26 \%)$ and preparing humour is quite time-consuming $(14 \%)$.

Teachers reported that collecting humorous materials in daily work and life in advance $(70 \%)$; making full use of network resource (29\%); classroom observations of teachers with a reputation for successfully using humour (24\%); preparing the teaching content in advance (21\%); reading books and articles about humour $(11 \%)$; and professional training provided by medical college $(4 \%)$ could improve their ability of using humour in the theoretical lecture.

\section{DISCUSSION}

In a teaching hospital, physicians usually serve the dual role of clinician and teacher with subject matter expertise and strong interest in student development. Ernest Leroy stated that a poor surgeon hurts one person at a time but a poor teacher hurts $130 .{ }^{3}{ }^{17}$ While effective teaching in medicine is essential to produce good quality doctors. ${ }^{25}$ Almost none of the physician teachers have professional training on how to teach or pass on knowledge effectively, much less teaching with humour. It has been established that the use of humour in medical education improves learning enthusiasm, consciousness, efficiency and quality. ${ }^{1526} 27$ Few studies thus far have been conducted on the perspectives of medical students and teachers on using humour in the theoretical lecture and what influences the use of humour in medical teaching. This study attempted to identify the attitude towards using humour in teaching and how to effectively use humour during class.

In the present study, $15 \%$ of students felt $80 \%$ of their classes were boring, $36 \%$ of students felt $60 \%$ of their classes were boring (table 1). We have to point out that knowing that the survey is about humour might influence student's answers and result in reporting bias. There is general agreement that theoretical lectures tend to be boring. ${ }^{28}$ Similar findings have been reported by UCLA's Higher Education Research Institute, with $35.6 \%$ of freshman students and $37 \%$ of seniors reporting being frequently bored in class. ${ }^{214} 17$ There are strategies like 
planning the course, conducting activities that appeal to all learning styles, creating a classroom with active participation of students, combining open-ended tasks and those with well-defined goals could help to improve the classroom environment. Cohen documented a high correlation between teaching efficiency and student's interest, with students becoming more attentive if humour was used in teaching, consistent with the current prevailing belief. $^{29}$

In the present study, $87 \%$ of students and teachers agreed with using humour in the theoretical lecture (table 2). Similarly, in a study by Torok et al only $2 \%$ of students did not believe in the usefulness of humour in classrooms. ${ }^{11}$ The students and teachers in the present study asserted that the use of humour created a relaxed classroom atmosphere, made learning enjoyable and enhanced learning effectiveness (table 2). Fostering a relaxed classroom atmosphere, obtaining self-satisfaction as a teacher and fostering joviality brought on by student's laughter were the main motivations for the teachers to use humour in teaching (table 5).

Teachers appeared to use humour in a variety of ways in the present study (table 2). Interesting clinical case was noted to be the most effective humour type, followed by ad libbed humour and cartoons, among those with the highest ratings (table 3). Relating learning to clinical cases seemed to be generally liked by medical students in clinical learning. It is quite amazing that interesting clinical case was noted to be the most popular type of humour both among teachers and students in the present study. Interesting clinical case could make learning experience more enjoyable and also focus on the teaching topic. When clinical case is entertaining and interesting, students retain more from teaching. ${ }^{30}$

There are different approaches to improving classroom environment by interesting clinical cases, including unusual case, detour that the mistake the doctor made during the process of diagnosing disease, the origin of medical terminology, etc. For example, physician could deepen the knowledge of asymptomatic carrier through the story of Mary Mallon who infected seven families in 1906 with the typhoid, and impress students the conception of anatomical term Achilles through its derivation from the Greek god of war during the Trojan War.

Distinguishing what is appropriate and inappropriate humour in an educational culture is essential to become a qualified teacher. ${ }^{31}$ According to Wanzer and Torok approach to humour teaching, inappropriate humour conveying aggressive/hostile or sexual messages would be considered inappropriate by students. ${ }^{3}{ }^{11}$ Jayasuriya-Illesinghe $e t a l$ stated that negative interactions with teachers would harass students. ${ }^{32}$ This is similar to the findings of Passi, who found that students felt embarrassed and wished to never have a class with teachers who said sexually offensive or sarcastic jokes. ${ }^{33}$ Consist with previous studies, our study showed that more than $60 \%$ of students opposed mockery and sarcasm. For example, laughing at patient's or student's ignorance on disease was both considered to be inappropriate.

However, additional research by Chiarello, and Kaplan and Pascoe advocated the positive effects of laughter to remember content in the class. ${ }^{26}{ }^{34}$ In the present study, $64 \%$ of students held that they remembered more information over time when humour is used in the theoretical lecture. The importance of using humour that is associated with the teaching topic has been stressed by de Brito et al, and Chauvet and Hofmeyer. ${ }^{816}$ Our study also found that most students emphasised that humour should contribute to the teaching topic. Humour which was irrelevant to the subject might be a waste of time and distract student's attention (table 4).

Humour in the theoretical lecture could be divided into two categories: high risk and low risk. ${ }^{17}$ Ad libbed humour is a high risk type of humour because it is most likely to fail to elicit laughter, and teachers might feel depressed or frustrated when the humour falls flat. ${ }^{17}$ Even worse, ad libbed humour unrelated to the subject may be distracting. Ziegler listed seven examples of basic types of low-risk humour: planned ad lib that are not spontaneous, cartoons, quotations and questions, top 10 lists, multiple-choice items, skits or dramatisations and anecdotes. ${ }^{17}$ Except for much higher chance to get laugh, elaborately planned ad lib could also focus on the subject and avoid distraction. However, in the present study, ad libbed humour is the second most frequently used type of humour by teachers (table 2) and also the second most effective type ranked by students (table 3). In a word, teachers preferred to use spontaneous ad lib rather than planned ad lib. Moreover, students felt planned ad lib was acceptable in the present study (table 3).

Very few studies have focused on the difficulties and challenges that physicians may face during teaching. Physician teachers in this study were asked to identify the type of challenges they faced while transmitting a humorous message. Lacking appropriate humour material related to clinical skills (course material) was ranked at the top, and that this challenge might be addressed by collecting humorous materials in daily work and efficiently using the internet. In the present study, physician teachers also affirmed that using humour in the theoretical lecture is influenced by lack of skills. Previous studies have attempted to address these challenges. Hueppchen et al stated that most of the medical faculty learnt to teach by observing their mentors or their teachers. ${ }^{35}$

\section{Limitations}

While the present study provides insight into the use of humour in medical education, it has some limitations. First, it is a single-centre study on a relatively small study population. Second, the present study relies on the memory of the participants completing the questionnaire. A crucial limitation of this approach is the possibility of recall bias. Participants may not have recalled information accurately. Third, knowing that the survey is about humour might result in reporting bias. we note this as a 
potential study limitation. Fourth, teachers and students may have different understanding about humour. Further studies are needed to explore the correlation of what teachers thought was funny and what students thought was funny.

\section{CONCLUSION}

The present study extends our knowledge of medical student and physician teacher's opinions on using humour in the theoretical lecture and identifies appropriate and inappropriate humour behaviours. By sharing ideas, perspectives and benefits related to using humour in the theoretical lecture, the findings of this study might be of benefit to assist physician teachers in using humour appropriately to successfully establish good lecture courses.

Acknowledgements We would like to acknowledge the volunteers who participated in our study in Tongji Medical College, and those who participated in our research design, date collection, date analysis and manuscript writing or reviewing.

Contributors $\mathrm{X}-\mathrm{QQ}$ and $\mathrm{LS}$ designed the study and the questionnaire and drafted the paper. Y-PL participated in data gathering, analysis and interpretation. X-FW and YY implemented the study and helped some of the data analysis. H-LZ and C-TZ took part in the discussion and modification of the design and the questionnaire. All authors have seen and agreed to the submission of the final manuscript.

Competing interests None declared.

Patient consent Obtained.

Ethics approval Ethics Review Board of Tongji Hospital, Tongji Medical College, Huazhong University of Science and Technology.

Provenance and peer review Not commissioned; externally peer reviewed.

Data sharing statement No additional data are available.

Open Access This is an Open Access article distributed in accordance with the Creative Commons Attribution Non Commercial (CC BY-NC 4.0) license, which permits others to distribute, remix, adapt, build upon this work non-commercially, and license their derivative works on different terms, provided the original work is properly cited and the use is non-commercial. See: http://creativecommons.org/ licenses/by-nc/4.0/

(c) Article author(s) (or their employer(s) unless otherwise stated in the text of the article) 2017. All rights reserved. No commercial use is permitted unless otherwise expressly granted.

\section{REFERENCES}

1. Tolsgaard MG, Ku C, Woods NN, et al. Quality of randomised controlled trials in medical education reported between 2012 and 2013: a systematic review protocol. BMJ Open 2014;4:e005155.

2. Sax LJ, Astin AW, Korn WS, et al. The American freshman: national norms for fall 1997. Los Angeles: Higher Education Research Institute, Graduate School of Education \& Information Studies, University of California, 1997.

3. Wanzer MB, Frymier AB. The relationship between student perceptions of instructor humor and students' reports of learning. Commun Educ 1999;48:48-62.

4. Salajegheh A, Jahangiri A, Dolan-Evans E, et al. A combination of traditional learning and e-learning can be more effective on radiological interpretation skills in medical students: a pre- and postintervention study. BMC Med Educ 2016;16:1-7.

5. Allen D, Abourbih J, Maar M, et al. Does a one-day workshop improve clinical faculty's comfort and behaviour in practising and teaching evidence-based medicine? a canadian mixed methods study. BMJ Open 2017;7:e015174.

6. Barnett-Vanes A, Ho G, Cox TM. Clinician-scientist MB/PhD training in the UK: a nationwide survey of medical school policy. BMJ Open 2015;5:e009852.
7. Piemonte NM. Last laughs: gallows humor and medical education. $J$ Med Humanit 2015;36:375-90.

8. de Brito CM, Silveira R, Mendonça DB, et al. Humor and laughter in health promotion: a clown insertion experience in the family health strategy. Cien Saude Colet 2016;21:553-62.

9. Riesch $\mathrm{H}$. Why did the proton cross the road? Humour and science communication. Public Underst Sci 2015;24:768-75.

10. McCoy L, Pettit RK, Lewis JH, et al. Evaluating medical student engagement during virtual patient simulations: a sequential, mixed methods study. BMC Med Educ 2016;16:1-15.

11. Torok SE, McMorris RF, Lin W-C. Is humor an appreciated teaching tool?perceptions of professors' teaching styles and use of humor. College Teaching 2004;52:14-20.

12. Prideaux D, Alexander $\mathrm{H}$, Bower $\mathrm{A}$, et al. Clinical teaching: maintaining an educational role for doctors in the new health care environment. Med Educ 2000;34:820-6.

13. Wallace S, Clark M, White J. 'It's on my iPhone': attitudes to the use of mobile computing devices in medical education, a mixed-methods study. BMJ Open 2012;2:e001099.

14. Banas JA, Dunbar N, Rodriguez D, et al. A review of humor in educational settings: four decades of research. Commun Educ 2011;60:115-44.

15. Naftulin DH, Ware JE, Donnelly FA. The doctor fox lecture: a paradigm of educational seduction. J Med Educ 1973;48:630-5.

16. Chauvet $S$, Hofmeyer A. Humor as a facilitative style in problembased learning environments for nursing students. Nurse Educ Today 2007;27:286-92.

17. Ziegler JB. Humour in medical teaching. Med J Aust 1999;171:579-80.

18. Ware JE, Williams RG. The Dr. Fox effect: a study of lecturer effectiveness and ratings of instruction. J Med Educ 1975;50:149-56.

19. Ziv A. Teaching and learning with humor: experiment and replication. $J$ Exp Educ 1988;57:5-15.

20. Zillman RR, Bushuk W. Wheat cultivar identification by gliadin electrophoregrams. II. effects of environmental and experimental factors on the gliadin electrophoregram. Can J Plant Sci 1979:59:281-6.

21. Martin RA, Puhlik-Doris P, Larsen G, et al. Individual differences in uses of humor and their relation to psychological well-being: Development of the Humor Styles Questionnaire. J Res Pers 2003;37:48-75

22. Proyer RT, Flisch R, Tschupp S, et al. How does psychopathy relate to humor and laughter? Dispositions toward ridicule and being laughed at, the sense of humor, and psychopathic personality traits. Int J Law Psychiatry 2012;35:263-8.

23. Buxman K. Humor in critical care: no joke. AACN Clin Issues 2000;11:120-7.

24. Sutkin G, Wagner E, Harris I, et al. What makes a good clinical teacher in medicine? A review of the literature. Acad Med 2008;83:452-66.

25. Del Mar C, Glasziou P, Mayer D. Teaching evidence based medicine. BMJ 2004;329:989-90.

26. Chiarello MA. Humor as a teaching tool. Use in psychiatric undergraduate nursing. J Psychosoc Nurs Ment Health Serv 2010;48:34-41.

27. Sperlazza E, Cangelosi PR. The power of pretend: using simulation to teach end-of-life care. Nurse Educ 2009;34:276-80.

28. Qiao $Y Q$, Shen J, Liang $X$, et al. Using cognitive theory to facilitate medical education. BMC Med Educ 2014;14:547-8.

29. Cohen PA. Effectiveness of student ratings feedback and consultation for improving instruction in dental school. J Dent Educ 1991;55:145-50.

30. Gifford $H$, Varatharaj A. The Elephant criteria in medical education: can medical education be fun? Med Teach 2010;32:195-7.

31. Hecht L, Buhse S, Meyer G. Effectiveness of training in evidencebased medicine skills for healthcare professionals: a systematic review. BMC Med Educ 2016;16:103.

32. Jayasuriya-Illesinghe V, Nazeer I, Athauda L, et al. Role models and teachers: medical students perception of teaching-learning methods in clinical settings, a qualitative study from Sri Lanka. BMC Med Educ 2016;16:1-8.

33. Passi V, Johnson S, Peile E, et al. Doctor role modelling in medical education: BEME Guide No. 27. Med Teach 2013;35:e1422-36.

34. Kaplan RM, Pascoe GC. Humorous lectures and humorous examples: Some effects upon comprehension and retention. J Educ Psychol 1977;69:61-5.

35. Hueppchen N, Dalrymple JL, Hammoud MM, et al. To the point: medical education reviews-ongoing call for faculty development. Am J Obstet Gynecol 2011;205:171-6. 